\title{
PROGRAMS FOR PREVENTION AND MANAGEMENT OF NATURAL DISASTERS IN THE EUROPEAN COUNTRIES OF THE LARGER AREA OF THE BLACK SEA BASIN
}

\begin{abstract}
Rusu Marcel ${ }^{1}$
Keywords: landslides, floods, earthquakes, hazard assessment, risk mitigation.

Abstract. The hazards that have cross-border consequences and represent a great problem for communities, become an obstacle to sustainable development and lead to disasters when combined with vulnerability and insufficient capacity to mitigate the risk. A short overview of research already implemented and in progress presents us a shift in systematic evaluation of the hazards and disasters at local and areal level. Hazard assessment of natural disasters (earthquakes, landslides and floods) on these scales can give results which can be directly used to take right decisions regarding preventive measures and plan effective actions of post-event management. The issue is widely recognized in the european union (eu) implicitly also in the black sea area, and a lot of efforts have already been made to mitigate the effects of disasters, obviously through the formation of numerous eu institution, established organizations and funded projects. The key elements for an effective mitigation of natural disasters are hazard identification and risk assessment, which must be based on scientifically grounded methodologies, reliable and accurate data. Successful resolution of the issues mentioned above will provide the ability to systematically assess natural disasters on regional and local scales, even in cross-border areas, by providing comparable hazard maps that will support the decision-making process in relation to mitigation measures required. The effective way of action against them is by providing applied research and technology transfer between partners in different countries by solving the problems such as lack of reliable information and lack of 'common ground' in the methodologies used to assess natural hazards and adopted procedures for mitigation.
\end{abstract}

\section{Objectives and conditions}

Natural hazards particularly in the form of earthquakes, landslides and floods pose a serious threat to society and sustainable development in the European Union (EU) and the Black Sea[1], [2] area. These risks may lead to natural disasters, if

\footnotetext{
${ }^{1}$ PhD student, Alexandru Ioan Cuza University, Iași,
} 
they are combined with an insufficient capacity of the risk reduction. The problem is widely recognised by the EU (Greece, Bulgaria and Romania) and non - EU countries of the Black Sea area (Turkey, Ukraine, Georgia, Russia and Moldova) and a lot of efforts have been spent to mitigate the effects of disasters, through an ongoing effort to reduce the impact of disasters on people and property. Mitigating the effects of disasters as a management process is usually divided into pre-event

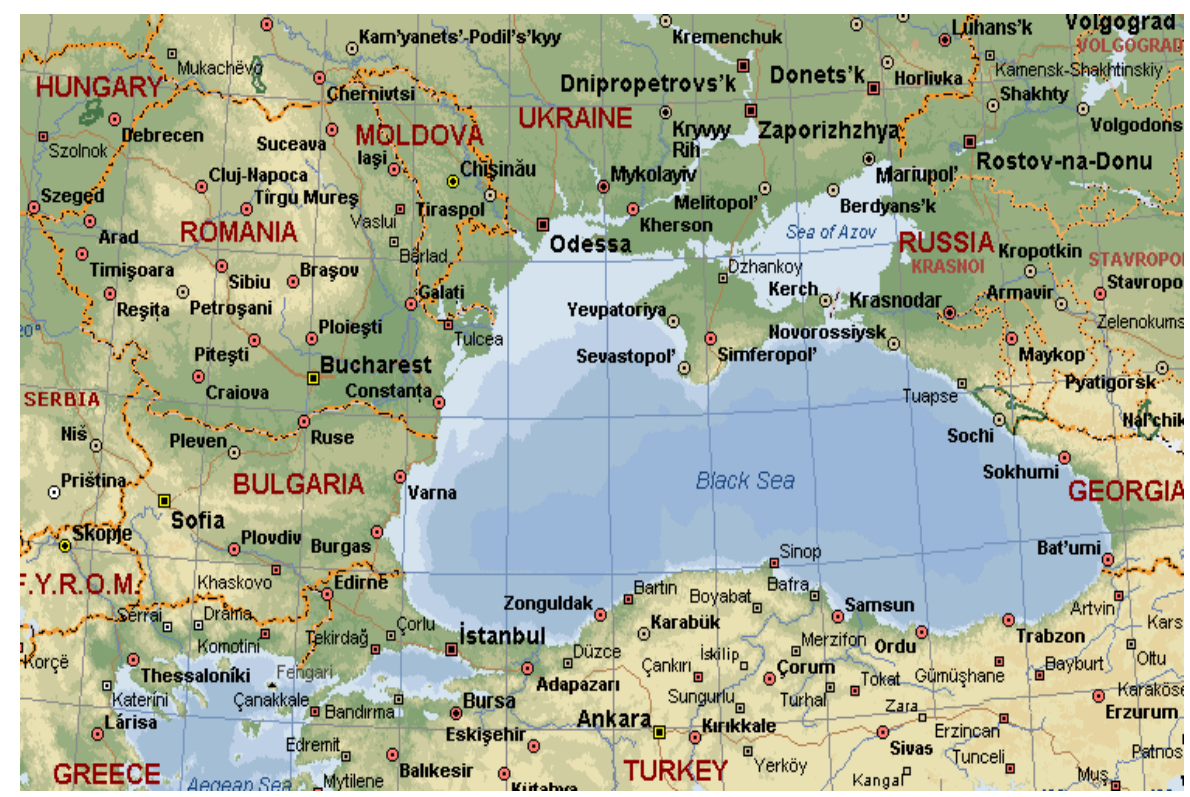

Fig.1 Physical - geographical map of countries in the extended area of the Black Sea basin

measures - actions taken during and immediately after an event and post-disaster measures, all classified into four basic stages - prevention, preparation, response and recovery. Pre-event measures are the most profitable, provided that they should be based on accurate and reliable identification of the hazards and risk assessment for the remaining stages of the mitigation process. Therefore, identification of the hazard and risk assessment can provide the framework needed for an effective prevention of natural [3], [4] hazard. The particular significance of these parameters in all stages of hazards underlines the need for their assessment, which must be based on accurate and scientifically proven data (after being adapted to local conditions, tested and accepted) and on appropriate methodologies. The purpose of this study is to give an overview of past actions and to assess current and future trends in natural risk mitigation in the EU and neighboring countries in the wider Black Sea Area (Fig.1). 
2. Risk management of earthquakes, flood and slipping of the land in the EU - the assessment of the current status

Natural disasters in EU and the neighboring countries of the Black Sea constitutes a serious threat to the life, property and infrastructure. One of the main challenges faced by the EU, is due to the fact that member states are at different levels of risk in terms of natural disasters, so that occur cohesion [5] problems. In terms of the vulnerability to natural disasters, it is constantly growing, due to population growth and the expansion of construction (urban, infrastructure, industrial), with urgent need for the EU to find solutions to the problem by promoting disaster [6] mitigation.

3. The actions of the countries belonging to the European Union research and major networks

In terms of research and implementation, a lot of efforts have already been made with very good results by the EU and by each country. An indicative list of EU created institutions, the established organizations and other international agreements, includes: EUR-OPA Major Hazards Agreement [7], the European Advisory Evaluation Committee for Earthquake Prediction (EAECEP), the European Warning System (alarm), and its subsidiary the European-Mediterranean Seismological Centre (CSEM / EMSC)[8], Joint Research Centre (JRC) [9] ,European Flood Alert and Monitoring System [10], as well as those provided by the Exchange Circle on Flood Forecasting, The circle of European exchange for the Mapping of Floods, The action of the flood prevention and the international framework agreements such as UNECE Water Convention and The Associated program of Flood Management [11].

\section{EU Policies and Initiatives}

EU actions have already focused on three general policy, cooperation and research axes and implementation.EU policies have been promoted through EU directives, strategies, established bodies, established organizations and funding programs, which led to the implementation of several research projects. Regarding the strategies for mitigating the risks of natural disasters, among the issued EU directives is The assessment of the effects of certain plans and programmes on the environment (DIRECTIVE 2001/42/EC), which, even addresses issues related to the protection of the environment, this implies the action to minimise the risks of natural disasters. The directive urges member states to take into account disaster risk reduction. A serious problem with the implementation of the Directive is the lack of a common pan-European methodological approach to risk assessment and risk mapping, so that comparable results and preventive measures, especially in cross-border areas, can not be produced or even planned. Convention on the Protection and use of Transboundary watercourses and International Lakes-Water Convention has led to the establishment of capacity building activities, such as 
"Working Group on the prevention and protection against floods", which in turn has led to the adoption of the "Guidelines on Sustainable Flood Prevention" at the meeting of the parties to the Convention of 2000. As a result of this action, the guidelines complemented by the model of the provisions on Cross-border Flood Management (2006) have led to the Directive 2007/60 / EC of the European Parliament and of the European Council( of 23 October 2007) on the assessment and management of floods risk[12], [13]. Floods Directive [14] is applied at this stage and covers only a preliminary assessment of flood risk, with a more or less descriptive nature [15]. According to the Directive, the flood risk assessment in a river basin will take place at a later stage after providing valuable information as long as comparable results are provided in all member states. This requirement makes the harmonisation of methodologies for the assessment of flood risk and data, as well as the acquisition of systematic data, to be absolutely necessary.

In terms of earthquake risk, European codes drawn up by the European Committee for Standardisation, provides a basis for the construction specifications and contracts the engineering and form a framework for the creation of technical specifications, harmonized standards for construction. In particular, the European Code 8 [16] that approaches the design of the structures for the resistance at the earthquake, it is in fact a preventive measure to diminish the risk of earthquake. Also related to the earthquakes is the report of the "Committee of energy research and technology" concerning the creation of a European research area and the measures to regional planning for protection against earthquakes (the European Parliament, DOC_EN RR 244682 244, 31.1.1994) [17].

Also, different EU interventions are expected in the form of thematic strategies. The Soil Thematic Strategy (STS), which attempts to address soil erosion and landslide risks has as objective the identification of high risk areas and to establish programs to reduce this risk. The Soil Thematic Strategy has 'struggled' for many years to become a 'directive' but without any results yet, so there is a gap in the implementation of the strategy. That being said, land use planning, which is a precondition for efficiency attenuation of the natural disasters risks, is missing in the EU's reference policy.

Funding programmes, such as the European Observation Network for Territorial Development and cohesion programme (ESPON), Copernicus [18] (previously known as GMES - Global Monitoring for Environment and Security) provides the basis for preventive action planning such as INSPIRE [19], 'natural risk zone section', which provides the framework for data reporting related to the natural hazard. A proposal for a directive on the protection of European Critical Infrastructure was made in 2006, but the framework for deciding on the priority sectors that need to be protected and the selection relative criteria has not been completed. 
Additional actions, including the international strategy for disaster reduction expressed in the Hyogo action plan 2005-2015 [20] (the World Conference in Kobe, 2005), the International Council for Science - ICSU natural hazards and human-induced environmental impacts (stage 2006-2012) and the International Year of Planet Earth (Unesco) and the GEO - Group of Earth observation - GEOSS (with an implementation plan of 10 years), were launched by the EU in cooperation with other international organizations.

A number of structural funds and cohesion policies have been used to promote research to mitigate the risks of natural disasters. The European Regional Development Fund (ERDF) in the European Territorial Cooperation Programs, including the "EU Strategy for the Danube Region", has been used to promote cohesion between Member States as well as risk mitigation. Although the prevention of hazards from natural disasters seems to capture the attention of more and more, a plan of EU or even guidelines to support the measures for prevention or reduction of risk, are missing.The European Union Solidarity Fund (EUSF), which was created following the flooding extended from Central Europe in 2002, has been established to support major natural disasters and to provide assistance to Member States [21]. Since 2002, it has funded the reconstruction of 56 disasters, including floods, forest fires, earthquakes, storms and drought. On the other hand, efforts to finance prevention actions are very limited.

Additional funding instruments include LIFE+ programmes and Civil Protection Financial Instrument (CPFI), which proved to be limited in terms of resources to support the strategies for the prevention of hazards from natural disasters. The EU's framework programmes for research and development have funded a series of research projects related to the dangers of natural disasters [22], since 1998 to present. After each period of implementation of a program, evaluation of the results and its evaluation has led to the identification of objectives to be investigated in mitigation of risks of natural disasters. These problems, in all cases have become the main objectives of the next programme, so it seems that there is a continuity in the Framework Programmes from FP5 to FP6 and then FP7. It is interesting to note that, in the first two programs (FP5 and FP6), the attempt to investigate the flood problem, focusing mainly on historical information and realtime flooding, was acknowledged that work had to be done in the development of european databases, including the monitoring of extreme events and their consequences [23].

The potential future research priorities, following the implementation of the FP6 program, included the study of sedimentation / detritus generation and extreme flood propagation; probabilistic real-time of multiple danger events; feasible options for extreme floods; non-invasive technologies to measure flood defense infrastructure and the performance of sewer systems during storm and intense 
rainfall. FP7, which followed, as well as projects funded by other EU bodies and financial instruments, focused exactly on the above mentioned objectives, providing valuable results on the mitigation of natural hazards and in particular on the evaluation of hazards and on the use of new technologies for hazard assessment.

Table 1. Research projects funded by the European Union, classified based on the main objectives and results

\begin{tabular}{|c|c|c|c|}
\hline \multirow{3}{*}{$\begin{array}{l}\text { The basic } \\
\text { objectives of } \\
\text { the project } \\
\text { Communication } \\
\text {, cooperation }\end{array}$} & \multicolumn{3}{|c|}{ Danger investigated } \\
\hline & Earthquake & Landslides & Floods \\
\hline & $\begin{array}{c}\text { CHRISHOPE, } \\
\text { NERIES, } \\
\text { REAKT, } \\
\text { SERIES }\end{array}$ & $\begin{array}{c}\text { CAPHAZNE } \\
\text { T, MATRIX, } \\
\text { PERPETUAT } \\
\text { E }\end{array}$ & 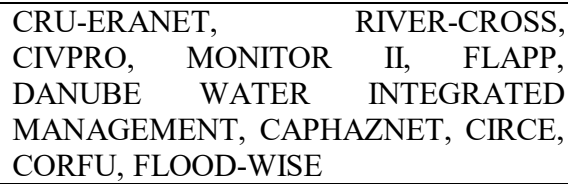 \\
\hline $\begin{array}{l}\text { Assess risk and } \\
\text { vulnerability by } \\
\text { designing } \\
\text { prevention } \\
\text { measures } \\
\end{array}$ & $\begin{array}{l}\text { SHARE, } \\
\text { SYNER-G }\end{array}$ & $\begin{array}{l}\text { LAMPRE, } \\
\text { SAFELAND }\end{array}$ & $\begin{array}{l}\text { SPHERE, DANUBE FLOODRISK PLAN } \\
\text { FOR PREVENTING FLOOD, } \\
\text { PROTECTION AND MITIGATION IN } \\
\begin{array}{l}\text { DOBROGEA LITTORAL, FLOOD } \\
\text { PROBE }\end{array}\end{array}$ \\
\hline $\begin{array}{c}\text { Disaster } \\
\text { preparedness } \\
\text { and } \\
\text { management }\end{array}$ & $\begin{array}{c}\text { TEFER, } \\
\text { CATALYST } \\
\text { SENSUM }\end{array}$ & RISKLIDES & $\begin{array}{l}\text { TEFER, RIBAMON, } \\
\text { FLINKMAN, VULMIN } \\
\text { FLOODRELIEF, DESWAT, RO_FFG, } \\
\text { FREEMAN, MEDIATION, SMARTEST, } \\
\text { STAR-FLOOD }\end{array}$ \\
\hline $\begin{array}{l}\text { Early warning } \\
\text { systems }\end{array}$ & SEAHELLARC & GALAHAD & $\begin{array}{l}\text { EFFS,FOODMAN OBSERVATION ON } \\
\text { ERYTHROPOTAMOS, } \\
\text { ARDAFORECAST, FLIRE, HYDRATE } \\
\text { (ON FLASH FLOODS - FF), FLASH, } \\
\text { URBANFLOO }\end{array}$ \\
\hline $\begin{array}{c}\text { Study of } \\
\text { associated } \\
\text { phenomena }\end{array}$ & TRANSFER & $\begin{array}{l}\text { IRASMOS, } \\
\text { RUNOUT }\end{array}$ & $\begin{array}{l}\text { FLOODSITE, IMPRINTS,IRASMOS } \\
\text { FF) }\end{array}$ \\
\hline $\begin{array}{l}\text { Development of } \\
\text { methodologies }\end{array}$ & $\begin{array}{c}\text { LESSLOSS, } \\
\text { SAFER, } \\
\text { MOVE, } \\
\text { MATRIX } \\
\end{array}$ & $\begin{array}{c}\text { RUNOUT } \\
\text { LESSLOSS, } \\
\text { MOVE, } \\
\text { RAMSOIL } \\
\end{array}$ & MOVE,ACTIFF,CONHAZ,MATRIX \\
\hline
\end{tabular}

During 2008-2009, the EU Commission focused on enhancing disaster response capacity. Several projects (over 50) were funded by the Joint Research and Information Society (CORDIS) in various calls (programs) focusing on climate, natural disasters, risk assessment and mitigation. Many projects have been and are funded through the European Neighbourhood and Partnership Instrument (ENPI) and the Instrument for Pre-Accession Assistance (IPA), including 
interregional projects (INTERREG, the 2007-13 Joint Operational Program for the Black Sea Basin).

The results of the research projects implemented and funded by all the abovementioned programs, as defined by the European Commission, suggests that there is a need for an integrated approach to natural disasters through prevention and management of hazards in the event of a disaster in a complete way of mitigation of the natural risks and should be - prevention, preparedness, response, recovery [24]. The proposed approach to the mitigation of risks suggests that prevention is the main objective accompanied by impact assessment in a way where planning of preventive measures leads to effective preparedness and response.

The specific objectives set for the future by the European Commission include actions that fall within three axes the development of knowledge based on prevention policies; the link between actors and policies throughout the disaster management cycle, as well as improving the efficiency of existing financial and legislative instruments. The European Parliament resolution of September 2010 provides support to the Commission's priorities for better risk awareness, better coordination of all actors and efficient and innovative funding.

The Commission Staff Working Paper Risk Assessment and Mapping Guidelines for Disaster Management issued by the European Commission (2010) suggests that risk assessments 'are crucial to improving prevention and preparedness activities against disasters and should contribute significantly to planning and building capacity. ' The main purpose of these guidelines and the biggest challenge is to improve the consistency between the risk assessment carried out in the EU Member States at national level at all stages of the risk mitigation cycle in order to make these risk assessments more comparable between EU Member States.It is expected that this approach will lead to greater transparency in the communication on hazards and will make cooperation in efforts to prevent and mitigate feasible common risks. Such risks as cross-border risks are still very difficult to mitigate due to the lack of comparability of the results assessment of risk disasters. As it turns out, the Council and the European Parliament have established as top priorities, those related to prevention of hazards, risk assessment and mapping by improving existing sources of information about the dangers of natural disasters.

These priorities set out by the European Parliament and the Council for the coming years include : a program of best practices, with the aim of leading to EU guidelines on minimum standards for disaster prevention (2012); an overview of major EU risks that it may face in the future (2012); and the support of this tool of governance, as part of the EU cooperation in the management of disaster risk with the European Commission's cooperation with UNISDR and OECD (2013). 


\section{Implemented research projects}

A brief overview of EU-funded and completed research projects is representative as the implementation stage that followed the policies and initiatives mentioned above. Information about projects with regard to the basic objectives, implementation and results have been collected from various sites and not only: the Framework Programmes of the EU Commission (FP5 / Cordis, FP6, FP7), the JRC (Joint Research Centre), web sites INTERREG. In this context, have been reviewed in more than 50 projects related to risk mitigation of natural disasters and classified according to the objectives and their results, as seen from a long-range.The acronym of the projects by classification categories is presented in Table 1. Each of the projects appearing in this table is mentioned once for each of the natural disaster hazards.

From the "temporal" evolution of the implemented projects,of their goals and objectives, it is obvious that research and implementation over the last twenty years has progressed since the initial stage, to establish cross-border cooperation between EU countries, to develop methodologies, to assess each of the dangers of natural disasters and then to the development of more effective management plans, and ultimately to the development of early-warning systems and the use of contemporary technologies.

A basic situation that appears to be missing, which is normal, considering the time and money required for its implementation, is the 'preventive measures' project. An effective preventive design measure requires local scale hazard assessment and projects already implemented, may in some cases, include such implementation because it only has to cover restricted areas as it is presented in several case studies carried out on larger areas. There is no assessment of systemic hazards at local scales.

Earthquakes are major natural hazards especially for southern Europe, including the Mediterranean and the Black Sea. The EU has recognized the importance of reducing seismic risk and has actively supported EU countries by legislating and funding projects that have led to significant scientific and technological achievements. The problem that remains is the issue of cross-border cooperation, which is common among efforts to mitigate natural hazards. A goal of the future ,in this regard, could be the development of policies to strengthen crossborder cooperation in terms of strategies of mitigation of the hazards by the earthquake (including prevention and management). To this end, policy-making is essential at government level in order to legislate properly in each of the participating countries. Also, there is a need for technology transfer with the aim of improving rescue methods and developing new technologies in helping to reduce the impact of disasters on life and property.In addition, it is necessary a land-use planning. In any case, the identification of earthquake hazards plays an important 
role, so it needs to be evaluated using widely accepted, reliable and accurate methodologies supported by equally reliable and accurate data.

For a more practical solution, the threat of earthquake could be assessed not only as an estimate of the earth's parameters (i.e. the maximum of the accelerating of the earth, the maximum speed of the plates, etc.), but as an assessment of the impact of the tellurian movement, in terms of geotechnical hazards caused on the land itself. Maps of potential danger, including the liquefaction, the side to side movement, and maps on the establishment of the soil can also be created and used to make effective decisions on taking the necessary preventive measures to avoid future problems, potential land uses, optimize construction legislation and raise public awareness.

The extensive list of projects related to the flood financed by the EU indicates the extent of the problem in all of Europe, including in the Black Sea area. Cooperation has been established, methodologies were developed and the use of contemporary technologies has led to the development of early warning systems. Floods on large rivers have been investigated in detail and management plans were accomplished.What seems to be lacking is the systematic assessment of flood hazard on a local scale, in order to develop custom preventive measures. Another partial problem is the danger of flash floods. Flash floods are typical in the mediterranean countries and the most common type of flooding in the central part and the southern part of the Black Sea area. They are sudden and violent phenomena that endanger life, property and infrastructure. The problem of flood hazard assessment is that flood-induced streams are usually ephemeral, with little or no water for most of the time, and these basins are generally of limited size and with a steep morphology, so this type of flood has to be addressed by applied research on a local scale.

As a result of the implementation of the projects prevention of landslides, european guidelines have been prepared for the recognition of landslides, to support decisions on land use planning. New technologies such as remote sensing and geographical information system (GIS) are widely applied for the assessment of susceptibility to landslides by assessing geological, hydrogeological and morphometric parameters which are affecting the stability of slope. Various modeling methods have been proposed to assess the threat of landslides in a more reliable and accurate manner, some of which are applied in the wider Black Sea area. EU-funded projects have examined the relationships between precipitation, land use, land cover and the slope failure event, and extensive erosion. The impact of climate change on the occurrence of landslides is also investigated. The ultimate goal of all the efforts with regard to the danger of landslides is to develop methodologies to predict the occurrence and impact of landslides. 
Additional issues remaining in regards to the dangers of natural hazards are related to information gaps, comparability of the results of the assessment and the issues related to cross-border issues. That being said, the unavailability of the required data is a double problem, whether there is no data at all or that the available data do not cover the full range (standards, inconsistency of measurements, time periods, etc.) or, finally, the available data are not comparable due to the different way of recording, processing or even coding by different researchers. Only two of the research projects have watched, examined, or attempted to establish guidelines for data harmonization within their broader objectives, but in general this issue remains unsolved. Most of the aforementioned problems have been recognized by the European Commission.

\section{Conclusions}

An overview of the EU actions related to the prevention and management of risks of earthquake, landslides and flood reveals the many actions undertaken in relation to legislative measures and structural, as well as the financing of a large number of research projects. These projects helped to establish co-operation, better understanding of processes during these natural phenomena, designing methodologies for modeling the risks of natural disasters and implementing research applied in many cases. Issues related to earthquake and landslide hazards are mostly national, where each country focuses mainly on relief and recovery measures. The local scale hazard assessment has been implemented in some cases in the form of microzoning studies, but in most of these cases there is no systematic risk assessment, nor preventive measures due to the economic cost.

The research applied on the risks of flooding have focused mainly on flooding riparian, probably due to the fact that this type of flooding, which is common in the countries of Central Europe, causing serious damage. As a result, measures have been planned effective for all stages of mitigation and have been developed systems of early warning. On the other hand, have been submitted only a few efforts to address the problem of floods fast which causes serious damage to southern European Union countries and the Black Sea area.

Another serious problem comes from the different methodological approaches used to assess the hazards of natural disasters in the countries bordering the Black Sea basin. They lead to incomparable results, and this problem is widespread, because different methodologies are often used by researchers even in the same country. In order to continue the concrete solutions for the reliable and correct assessment of hazards, this issue needs to be addressed as soon as possible. Achieving a consensus among the scientific community about the data and methodologies used for hazard assessment of natural disasters is in this case 
absolutely essential, because it will contribute to the creation of a wide network of potential partners with the same scope monitoring and prevention of hazards of natural hazards. In addition, it will provide them with the means to communicate transparently on related scientific issues.

Management strategies should also be harmonized as fully and quickly as possible. Risk management must follow all four stages of the risk management cycle. Cross-border cooperation, especially when considering the danger of floods, is needed at every stage of the process, as it will greatly contribute to the efficient resolution of the problem for the benefit of all partners. Cooperation, in any case, helps to increase the number of available solutions, strengthen the knowledge base and shared information between partners, and select more effective mitigation strategies. Issues that arise when considering cross-border cooperation in reducing flood risk are usually linked to the lack of a legal framework for cooperation, lack of capacity and resources, different institutional structures, lack of political will and lack of public awareness and participation. It is imperative to address all these problems and dysfunctions for better prevention.

Finally, it can be concluded that in order to assess the hazards of natural hazards in the countries of the Black Sea basin, cross-border cooperation, harmonization of the methodologies used, easy or even free access to reliable and accurate harmonized data, as well as accurate hazard maps on local level, to effectively design preventive measures, plan an effective management strategy, and ultimately increase public awareness to achieve an effective reduction of risks to natural hazards.

\section{References}

[1] European Commission, Humanitarian Aid and Civil Protection: Prevention http://ec.europa.eu/echo/funding-evaluations/financing-civil-protection/calls-forproposal_en

[2] United Nations Disaster Assessment and Coordination Organization (UNDAC): http://www.unocha.org/what-we-do/coordination-tools/undac/overview

[3] Commission of the European Communities: Communication from the Commission to the Council and the European Parliament: EU strategy to support disaster risk reduction in developing countries. COM (2009) 84 final, Brussels, 2009, p. 12.

[4] Council of the European Union: Council Conclusions on a Community Framework on Disaster Prevention within the EU 2979th JUSTICE and HOME AFFAIRS Council Meeting, Bruxelles, 2009, p. 8.

[5] European Commission for the Environment: Assessing the potential of a comprehensive Community strategy for the prevention of natural and man-made disasters. Final Report, 2008, p. 110.

[6] ClarK Ian, (European Commission): Towards an EU Policy on Disaster Management. Brussels, 2012, p.12. 
[7] EUR-OPA Major Hazards Agreement, http://www.coe.int/en/web/europarisks/specialised-centres

[8] Euro-Mediterranean Seismological Center (CSEM / EMSC): http://www.emsccsem.org/\#2/.

[9] Joint Research Center (JRC): http://ec.europa.eu/dgs/jrc/

[10] European Flood Monitoring System - EFAS: http://www.efas.eu/

[11] United Nations Economic Commission for Europe (UNECE): Convention on the Protection and Use of Transboundary Watercourses and International Lakes, Transboundary Flood Risk Management Experiences from the UNECE Region. New York \& Geneva, 2009, p. 98.

[12] European Commission: Research and Innovation: Managing the Risks of Flooding in Europe. Conference Proceedings, 2006, p. 307.

[13] European Commission: Faster and more accurate flood alerts thanks to EU research projects, Brussels, 2014, p. 2

[14] Commission: 2007/60/EC Directive Implementation: Preliminary Flood Risk Assessment, http://ec.europa.eu/environment/water/flood risk/implem.html

[15] E. MOSTERT, J. S. JUNIER: The European Flood Risk Directive: Challenges for Research. Hydrol Earth Syst Sci Discuss, 6, 4961 (2009).

[16] European Commission: Eurocodes, Eurocode 8, http://eurocodes.jrc.ec.europa.eu/doc/WS_335/report/EC8_Seismic_Design_of_Buildi ngs-Worked_examples.pdf

[17] Commission of the European Communities: Critical Infrastructure Protection. Reports and guidelines. Http://ec.europa.eu/energy/infrastructure/critical_en.htm.

[18] COPERNICUS: The European Earth Observation Program: http://www.copernicus.eu/project-database

[19] European Commission, INSPIRE: http://inspire.ec.europa.eu/

[20] European Climate Adaptation Platform: Business Case for Disaster Risk Reduction: http://www. preventionweb.net/english/hyogo/gar/2013/en/home/download.html.

[21] European Union Solidarity Fund (EUSF): http://ec.europa.eu/regional_policy/en/funding/solidarity-fund

[22] Directorate-General for Research: extract from DG rtD unit I.4. List of topics: Natural hazards - Flood risk research projects in the EU, Framework Program 5 (1998-2002), Environment and Sustainable Development Program and Framework Program 6 (2002-2006): "Sustainable Program Development, Global change and ecosystems), 2005 , p. 76.

[23] WMO / GWP: Integrated Flood Management Concept Paper. APFM Technical Document No 1, 2nd Ed. 2004, p. 29.

[24] Commission of the European Communities: Commission staff working document: Risk management and mapping guide for disaster management. European Commission, sec. (2010) 1626 final, p. 42, Brussels. 